\title{
Existence of competitive equilibrium under financial constraints and increasing returns
}

\author{
H. Nur Ata ${ }^{\mathrm{a}}$, Erdem Başç1 ${ }^{\mathrm{b}, *}$ \\ ${ }^{a}$ Department of Economics and Economic History, IDEA, Universitat Autónoma de Barcelona, \\ Barcelona, Spain \\ ${ }^{\mathrm{b}}$ Department of Economics, Bilkent University, Ankara, Turkey
}

Accepted 4 November 2003

\begin{abstract}
This paper studies a 'factor cost in advance' model with increasing returns in production. In the model both partial equilibrium and general equilibrium may exist since working capital of firms limit their input demand. We provide a sufficient condition for the existence of partial equilibrium of a firm operating on a non-convex choice set. Furthermore we establish the existence and uniqueness of competitive equilibrium in the special case of logarithmic utility.

(C) 2004 Elsevier B.V. All rights reserved.
\end{abstract}

JEL classification: C61; C62; D50; D40; E40

Keywords: Increasing returns; Limited participation; Money

\section{Introduction}

What determines the scale of operations of a firm? At which point does a firm stop expanding its production and sales? For an economist the answer to this question depends on the assumptions about technology on the one hand and competitiveness of the product and possibly factor markets on the other. In this paper we point attention to the usefulness of a third consideration, namely financial constraints, in determining the size of a firm.

Under constant and decreasing returns to scale in production, both perfect and imperfect competition are known as viable modeling approaches. Under perfect competition, price taking behavior prevails. In case of constant returns to scale technologies, at all levels of output, pure profits turn out to be zero in a general equilibrium and hence

\footnotetext{
* Corresponding author. Tel.: +90-312-2901469; fax: +90-312-2665140.

E-mail address: basci@bilkent.edu.tr (E. Başç1).
} 
the production level of a firm is determined solely by the quantity demanded. In case of decreasing returns to scale technologies, however, a firm stops expanding its output at a point where price of the product equals marginal cost. On the other hand, under imperfect competition, typically, the price of the product is assumed to fall rather fast with an expansion in output. Therefore the demand function and the associated decreasing marginal revenue function together with a non-decreasing marginal cost function determine the scale of operations.

Under increasing returns, however, imperfect competition and the corresponding monopolistic behavior has been considered as the only viable alternative in the literature. The reason is clear. Price taking cannot be compatible with partial equilibrium when marginal cost falls with output. The factor demands and product supply are unbounded, giving rise to unbounded economic profits.

In this paper, we explore the possible role of financial constraints in limiting the scale of operations of firms endowed with an increasing returns to scale technology. In a model with time dimension, it is quite natural to model the firms in a factor cost in advance (FCA) fashion. That is firms have to pay for their factors of production before they collect their sales revenue. The use of this timing assumption on cash flows is becoming more common in macroeconomic models. Fuerst (1992) is the first example in the monetary business cycles literature to use this assumption. Fuerst assumes a constant returns to scale technology and that operations are financed through short-term loans obtained from a competitive loan market. Barth and Ramey (2001) reviews the developments of this class of limited participation models and provides strong empirical support from time series data. Başçı and Sağlam (2003) explore the general equilibrium differences between the more traditional cash in advance (CA) models of the consumer and the factor cost in advance (FCA) of self financed firms under constant returns to scale technologies.

Empirical work, however, points to the presence of statistically significant increasing returns to scale at least in some industries. Basu and Fernald (1997) reports increasing returns in US durable goods manufacturing industry with a scale elasticity about 1.07. Using a large international trade data set, Antweiler and Trefler (2000) report scale elasticities in the range 1.00-1.40 for various sectors from world economies. The strongest scale elasticities they report are for petroleum and coal products (1.40), pharmaceuticals (1.31) and electric and electronic machinery (1.20).

Under increasing returns, Fuerst's (1992) approach of borrowing from the credit market cannot possibly be applied. At any given money market interest rate, the optimal credit demand is unbounded by the same reasoning as in paragraph 3 above. If such firms operate in a competitive world, there has to be a rationing of some sort on the financial side. For simplicity in this paper, we study the case of self financing. We assume that owners' initial money is used as working capital by the firm and revenue generated, in part, is distributed as dividends to owners and, in part, is retained by the firm as following periods' working capital. A very similar mechanism would work with banks extending and renewing commercial credit lines to firms under a credit rationing scheme.

Convexity of production sets is one of the basic assumptions of neoclassical general equilibrium theory. It is widely observed, however, that for many industries the 
decreasing returns assumption in production implied by convex technologies is far from reality. Due to this observation, the well-known non-existence problem of competitive equilibrium under non-convex technologies gave rise to two branches of literature, one motivated from a normative and the other from a positive viewpoint. The normative approach deviated from the profit maximization assumption in order to secure or approximate the fundamental theorems of welfare economics. Marginal cost pricing (e.g., Guesnerie, 1975; Beato, 1982; Khan and Vohra, 1987; Vohra, 1988, 1992) and average cost pricing (e.g., Brown and Geoffry, 1983) are two important lines of research in this spirit. The positive approach, on the other hand, gave up the price taking assumption for the firms, resulting in models of imperfect competition (e.g., Mankiw, 1985; Blanchard and Kiyotaki, 1987) in spirit of Chamberlin (1933). In this paper we also take a positive standpoint, but explore the possibility of keeping both the price taking assumption and the maximizing behavior of the firms in a model with financial constraints.

One of the main obstacles against the existence of an Arrow-Debreu equilibrium under increasing-returns-to-scale (IRS) technologies is the unbounded factor demands in face of a limited endowment of total factors of production. We eliminate this obstacle by reverting to a version of the limited participation models recently used in the business cycles literature (e.g., Fuerst, 1992; Christiano et al., 1997, 1998). In these models firm need cash at the beginning of a production cycle and they meet this need from a competitive loan market. Here, as in Başçı and Sağlam (2003) we study the case of self-financing under borrowing constraints. The presence of increasing returns is a natural reason for credit rationing since the loan demands are unbounded for any positive interest rate.

A second important obstacle is the loss of convenience from using the tools of convex analysis and convex programming, once increasing returns is allowed for. In this paper, our contribution is two-fold. First, we limit the labor demands by assuming internal financing via owners' equity and retained earnings. Second, we study a non-linear programming problem on a non-convex feasible set. The results are promising, indicating that usual Euler equations may be useful, even under increasing returns to scale, provided that the utility function is sufficiently concave to avoid corner solutions.

The paper is organized as follows. In Section 2 the general model is presented as well as the sufficient condition for the existence of partial equilibrium of the producer. Section 3 gives the existence result for the competitive equilibrium. Section 4 conducts comparative statics and some quantitative assessment. Section 5 concludes with some remarks.

\section{The model}

In our hypothetical finite-horizon economy, at each time $t$, we have two agents with two different types; 'worker' and 'producer'. They differ in their access to production technology. There are two types of commodities: a factor of production, labor $L_{t}$ and a non-storable consumption good, apple $q_{t}$. Agent 1 (worker) has only labor 
endowment $\bar{L}>0$ and has no access to production technology. Agent 2 (producer) has no labor endowment and has an increasing returns to scale (IRS) technology $f_{2}(L)=L^{\gamma}$, $\gamma>1$, to convert labor into apples. One can have apples only through these production possibilities i.e. initially there are no endowment of apples.

Agents are indexed by $i=1,2$. Preferences of the agents over the consumption good, apple, are represented by the same instantaneous utility function $U$. We assume that neither one of the agents values leisure. The preferences over the lifetime consumption for both types of agents are given by an additively separable form $\sum_{t=0}^{T} \beta^{t} U\left(C_{i, t}\right)$, where $\beta \in(0,1)$ is the common discount factor, and $C_{i, t}$ is the consumption of agent $i$ at time $t$. We assume that $U$ is twice continuously differentiable $U^{\prime}()>$.0 and $U^{\prime \prime}()<$.0 . The economy operates with money under cash-in-advance constraints in both labor and apple markets. Money is perfectly storable and $M_{i, t}$ denotes the money holding of Agent $i$ at time $t$. We assume that initially all the currency in the economy, $M_{0}$, is owned by Agent 2, that is, $M_{1,0}=0$ and $M_{2,0}=M_{0}$. Total money stock does not change over time. The paper money is backed by the government with a promised price of $\left(1 / p_{2}\right)$ in the last period. This assumption is due to the finiteness of time horizon as explained below.

\subsection{Markets}

We will consider a market organization with three periods $(t=0,1,2)$. Each period, due to cash in advance constraints imposed on factor purchases, goods market opens after the labor market closes. In period 0, Agent 2, who initially has all the currency in the economy, purchases labor. Then Agent 2 produces apples with the IRS technology. After the production of apples is complete Agent 1 has money, Agent 2 has apples and goods market opens. Agent 2 sells part of his apples to Agent 1 in return for money and now both Agent 1 and Agent 2 has apples to consume. Agent 2 also has money to be used as working capital in the next period. In the last period, money held by agents is backed by the government by selling apples to them.

With the endowment structure described above and given the strictly positive prices $w_{t}, p_{t}$ for each period $t$, finite horizon utility maximization problem of the two agents can be written as

Agent 1 (Worker):

$$
\begin{aligned}
\text { (P1) } \max & \sum_{t=0}^{t=2} \beta^{t} U\left(C_{1, t}\right) \\
\text { s.t. } \quad & \text { for all } t=0,1,2, \\
& C_{1, t}=q_{t}^{d}, \\
& L_{t}^{s} \leqslant \bar{L}, \\
& M_{1, t+1}=M_{1, t}+w_{t} L_{t}^{s}-p_{t} q_{t}^{d},
\end{aligned}
$$

where $M_{1, t}, C_{1, t}, q_{t}^{d}, L_{t}^{s} \geqslant 0$ for all $t$ and $M_{1,0}=0$ is given. 


\section{Agent 2 (Producer):}

$$
\begin{aligned}
\text { (P2) } \max & \sum_{t=0}^{t=2} \beta^{t} U\left(C_{2, t}\right) \\
\text { s.t. } \quad & \text { for all } t=0,1,2, \\
& C_{2, t}=f\left(L_{t}^{d}\right)-q_{t}^{s}, \\
& w_{t} L_{t}^{d} \leqslant M_{2, t}, \\
& M_{2, t+1}=M_{2, t}-w_{t} L_{t}^{d}+p_{t} q_{t}^{s},
\end{aligned}
$$

where $M_{2, t}, C_{2, t}, q_{t}^{s}, L_{t}^{d} \geqslant 0$ for all $t$ and $q_{2}^{s}=0, M_{2,0}=M_{0}$ is given. In the last period, i.e. $t=2$, the producer will choose to set $q_{t}^{s}=0$ regardless of $p_{2} \geqslant 0$ determined by the government and hence $M_{2,3}=0$ since there is no period 3 where money can be used.

As an auxiliary assumption, suppose that $L_{t}^{d}=M_{2 t} / w_{t}$, that is, Agent 2 uses all of his money to purchase labor, ${ }^{1}$ then problem (P2) becomes

$$
(\mathrm{P} 2)^{\prime} \quad \max \sum_{t=0}^{t=2} \beta^{t} U\left(f\left(\frac{M_{2, t}}{w_{t}}\right)-\frac{M_{2, t+1}}{p_{t}}\right)
$$

s.t. for all $t=0,1,2$

$$
f\left(\frac{M_{2, t}}{w_{t}}\right)-\frac{M_{2, t+1}}{p_{t}} \geqslant 0
$$

and $M_{2, t} \geqslant 0$ for all $t, M_{2,3}=0, M_{2,0}=M_{0}>0$ and $\beta \in(0,1)$.

An equilibrium in this economy consists of a finite sequence of apple prices, money wages, labor demands, labor supplies, apple demands, apple supplies and money holdings by the two agents such that at each date, demands, supplies and money holdings are optimal under the given wage and price sequences, demand equals supply in both labor and apple markets and money holdings sum up to the total money supply at each time.

Formally, we say that $\left\langle p_{t}, w_{t}, L_{t}^{d}, L_{t}^{s}\right\rangle_{t=0}^{t=2}$ and $\left\langle q_{t}^{d}, q_{t}^{s}, M_{1, t+1}, M_{2, t+1}\right\rangle_{t=0}^{1}$ is an equilibrium if

(i) $\left\langle L_{t}^{s}\right\rangle_{t=0}^{2},\left\langle q_{t}^{d}, M_{1, t+1}\right\rangle_{t=0}^{1}$ solves (P1) and $\left\langle L_{t}^{d}\right\rangle_{t=0}^{t=0},\left\langle q_{t}^{s}, M_{2, t+1}\right\rangle_{t=0}^{1}$ solves (P2) under $\left\langle w_{t}, p_{t}\right\rangle_{t=0}^{2}$,

(ii) $L_{t}^{d}=L_{t}^{s} \forall t$,

(iii) $q_{t}^{d}=q_{t}^{s}$ for $t=0,1$,

(iv) $M_{1, t+1}+M_{2, t+1}=\bar{M} \equiv M_{0}$ for $t=0,1$.

Since at $t=2$ the goods market will clear with the intervention of government where the goods demand of workers is met by the government at price $p_{2}$, the variables $q_{2}^{d}$, $q_{2}^{s}$ and the corresponding $M_{1,3}$ and $M_{2,3}$ are excluded from the above definition.

\footnotetext{
${ }^{1}$ The validity of this assumption is verified by means of a 'profitability condition' later, in proof of Proposition 5 in Section 3.
} 
Most of the following analysis will be an attempt to find a solution to Agent 2's optimization problem. Therefore we will drop the index $i$ in variables of interest and the term 'optimization problem' will refer to Agent 2's optimization problem until Section 3.

\subsection{Producer's optimization problem}

Let $V: \mathbb{R}_{+}^{2} \rightarrow \mathbb{R}$ and $h_{i}: \mathbb{R}_{+}^{2} \rightarrow \mathbb{R}_{+}$for $i=1, \ldots, 5$ be defined as

$$
\begin{aligned}
& V\left(M_{1}, M_{2}\right)=U\left(f\left(\frac{M_{0}}{w_{0}}\right)-\frac{M_{1}}{p_{0}}\right)+\beta U\left(f\left(\frac{M_{1}}{w_{1}}\right)-\frac{M_{2}}{p_{1}}\right)+\beta^{2} U\left(f\left(\frac{M_{2}}{w_{2}}\right)\right), \\
& h_{1}=M_{1} \geqslant 0, \\
& h_{2}=M_{2} \geqslant 0, \\
& h_{3}=C_{0}=f\left(\frac{M_{0}}{w_{0}}\right)-\frac{M_{1}}{p_{0}} \geqslant 0, \\
& h_{4}=C_{1}=f\left(\frac{M_{1}}{w_{1}}\right)-\frac{M_{2}}{p_{1}} \geqslant 0, \\
& h_{5}=C_{2}=f\left(\frac{M_{2}}{w_{2}}\right) \geqslant 0,
\end{aligned}
$$

where $U$ is the twice continuously differentiable, instantaneous utility function satisfying $U^{\prime}()>0,. U^{\prime \prime}()<$.0 and $\lim _{c \rightarrow 0} U^{\prime}(C)=\infty . f$ denotes the IRS production function and satisfies $f^{\prime}(L) \geqslant 0, f^{\prime \prime}(L)>0$. All the parameters $\left\{w_{t}, p_{t}, M_{0}, \beta\right\}_{t=0}^{T=2}$ are assumed to be strictly positive, $\beta$ is the discount factor, $\beta \in(0,1)$. Note that the objective function $V$ is bounded from above.

Three period utility maximization problem of Agent 2 can then be reformulated as

$\max V\left(M_{1}, M_{2}\right)$ over the constraint set,

$$
\Gamma=\left\{\left(M_{1}, M_{2}\right) \in \mathbb{R}_{+}^{2} \mid h_{i}\left(M_{1}, M_{2}\right) \geqslant 0 \quad i=1, \ldots, 5\right\} .
$$

\subsubsection{Properties of the constraint set}

Fig. 1 shows the constraint set $\Gamma$ on the $\left(M_{1}, M_{2}\right)$ plane where $M_{1}, M_{2} \in \mathbb{R}_{+}^{2}$. It is easy to see that the set $\Gamma \subset \mathbb{R}^{2}$ is compact (closed and bounded) and non-convex. On the non-linear section of the boundary $M_{2}=p_{1} f\left(M_{1} / w_{1}\right)$ we have $C_{1}=0$, on the vertical line $M_{1}=p_{0} f\left(M_{0} / w_{0}\right)$ we have $C_{0}=0$ and the horizontal line $M_{2}=0$ is the set of points $\left(M_{1}, M_{2}\right)$ where $C_{2}=0$. At the corners which are numbered by $1,2,3$ we have $C_{1}=C_{2}=0, C_{1}=C_{0}=0, C_{2}=C_{0}=0$, respectively.

At point $\left(M_{1}, M_{2}\right) \in \operatorname{int} \Gamma$, the distance $d_{1}=p_{1} f\left(M_{1} / w_{1}\right)-M_{2}=p_{1} C_{1}$ measures the consumption at $t=1$ and $d_{2}=p_{0} f\left(M_{0} / w_{0}\right)-M_{1}=p_{0} C_{0}$ measures consumption at $t=0$. Distance from the point $\left(M_{1}, M_{2}\right)=\mathbf{x}$ to the horizontal line $\left(M_{1}\right.$-axis $)$, 


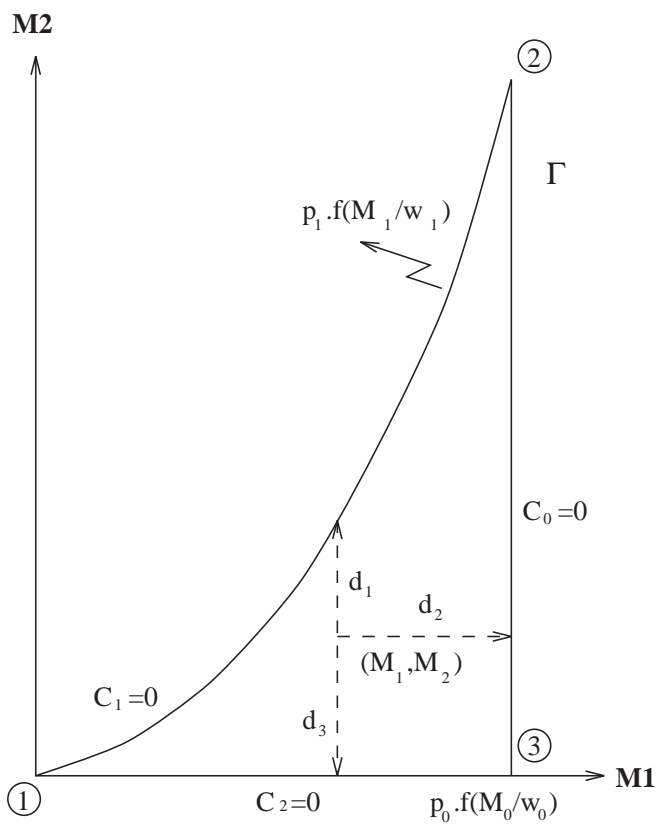

Fig. 1. Constraint set.

$d_{3}$, is a monotone transformation $g\left(C_{2}\right)$ of the third period consumption $C_{2}$. That is $d_{3}=M_{2}=w_{2} f^{-1}\left(C_{2}\right)=g\left(C_{2}\right)$. Note that the production function $f$ is a continuous, strictly increasing function (of $L$ ) hence it has an inverse and $f^{-1}=g$ is also monotone.

\subsubsection{Characterizing the solution of producer's optimization problem}

Inspection of the choice set illustrated in Fig. 1 reveals that Kuhn-Tucker-Lagrange (KTL) theory is not directly applicable to this problem. The the constraint set $\Gamma$ is not convex, therefore the KTL conditions are not sufficient for optimality. Moreover, corners 1 and 2 do not satisfy constraint qualification, so that KTL conditions are not even necessary on these corner points.

In order to avoid these technical problems, we impose the following condition on the utility function of the consumer, in addition to monotonicity, twice differentiability and strict concavity.

Condition $(*) . U(0)=-\infty$ and $\lim _{c \downarrow 0} U(c)=-\infty$.

This condition is satisfied, for example, by the logarithmic utility function and the more general constant relative risk aversion (CRRA) family. It is stronger than the usual Inada condition which requires the derivative of the utility function to approach plus infinity as consumption approaches zero. Therefore, for example, the utility function $U(c)=\sqrt{c}$ does not satisfy Condition $(*)$. The possibility of a corner solution and 
the failure of sufficiency of KTL conditions with the square-root utility example is elaborated in the appendix.

Proposition 1. Assume that the utility function $U: \mathbb{R}_{+} \rightarrow \mathbb{R}$ is twice continuously differentiable, monotone increasing, strictly concave on $\mathbb{R}_{++}$and satisfies Condition $(*)$. Let $V$ and $\Gamma$ be defined as in (1). At least one global maximizer $\mathbf{x}^{*}=\left(M_{1}^{*}, M_{2}^{*}\right) \in$ int $\Gamma$ of the inequality constrained problem $\max V\left(M_{1}, M_{2}\right)$ over the constraint set $\Gamma$ exists. Moreover, the point $\mathbf{x}^{*}$ satisfies the first-order (necessary) condition for a maximum, that is

$$
D V\left(\mathbf{x}^{*}\right)=0 .
$$

Proof. For a given $\varepsilon>0$ and a point $x \in \partial \Gamma$ define the open ball $B_{\mathbf{x}, \varepsilon}=\left\{\mathbf{x}^{\prime} \mid \| \mathbf{x}-\right.$ $\left.\mathbf{x}^{\prime} \|<\varepsilon\right\}$. Consider the set $\Gamma_{\varepsilon}=\Gamma \backslash \bigcup_{\mathbf{x} \in \partial \Gamma} B_{\mathbf{x}, \varepsilon}$. Clearly, there exists an $\bar{\varepsilon}>0$ such that the set $\Gamma_{\varepsilon}$ is compact and non-empty for sufficiently small values of $\varepsilon$, i.e. for $\varepsilon \in(0, \bar{\varepsilon}]$. Notice that $\Gamma_{0}=\Gamma$ and $\Gamma_{\bar{\varepsilon}}$ is a singleton in the interior of $\Gamma$. Let $\varepsilon \in(0, \bar{\varepsilon}]$ be given. Since the restriction of the value function $V$ on the compact and non-empty set $\Gamma_{\varepsilon}$ is continuous, by the Weierstrass Theorem, there exists a maximum of $V$ on this set. Let $V^{*}(\varepsilon)$ denote this maximum value. Now, by the Theorem of the Maximum, $V^{*}(\varepsilon)$ is a continuous function of $\varepsilon$ on the set $(0, \bar{\varepsilon}]$. It follows from its definition that $V^{*}$ is also a non-increasing function of $\varepsilon$. Moreover, as a result of Condition $(*)$, as $\varepsilon$ approaches zero, $V^{*}$ becomes flat, i.e. a constant function. This constant is the maximum of $V^{*}$ on $\Gamma$ as well, and it is attained by some $x^{*} \in$ int $\Gamma$. Since it is an interior point and since $V$ is differentiable, the gradient of $V$ has to vanish at $x^{*}$.

Remark 2. Note that this proof is valid regardless of the dimension and geometry of $\Gamma$, provided that $\Gamma$ is compact. This means that we have an existence result for the $n$-period economy. However there are technical difficulties in determining the uniqueness of the solution $\left(M_{1}, \ldots, M_{n}\right)$ to the first-order condition $D V\left(\mathbf{x}^{*}\right)=0$. Therefore we prefer to state the existence result for $n=2$.

The first-order condition (FOC) $D V\left(\mathbf{x}^{*}\right)=0$ is necessary for an optimum. In a given problem, if we also can prove that the FOC has a unique solution, we will have characterized the solution as a singleton in the choice set, $\Gamma$. We can openly write the FOC as the following set of Euler equations:

$$
\begin{aligned}
& -\frac{1}{p_{0}} U^{\prime}\left(f\left(\frac{M_{0}}{w_{0}}\right)-\frac{M_{1}}{p_{0}}\right)+\frac{\beta}{w_{1}} U^{\prime}\left(f\left(\frac{M_{1}}{w_{1}}\right)-\frac{M_{2}}{p_{1}}\right) f^{\prime}\left(\frac{M_{1}}{w_{1}}\right)=0, \\
& -\frac{\beta}{p_{1}} U^{\prime}\left(f\left(\frac{M_{1}}{w_{1}}\right)-\frac{M_{2}}{p_{1}}\right)+\frac{\beta^{2}}{w_{2}} U^{\prime}\left(f\left(\frac{M_{2}}{w_{2}}\right)\right) f^{\prime}\left(\frac{M_{2}}{w_{2}}\right)=0 .
\end{aligned}
$$

\subsubsection{Unique solution for logarithmic utility}

It is straightforward to check that the objective function $V$ satisfies Condition $(*)$ if we choose the instantaneous utility function $U(C)$ as logarithmic. Then Proposition 1 says that there exists an interior global maximum $x^{*}$ of $V$. For the uniqueness of $x^{*}$ 
we will use the following lemma, proof of which can easily be done by using ordinary calculus.

Lemma 3. Let $g_{1}, g_{2}:\left[x_{0}, \infty\right) \rightarrow \mathbb{R}, g_{1}, g_{2} \in C^{2}\left[x_{0}, \infty\right)$ be two functions satisfying the following conditions:

(i) $g_{1}\left(x_{0}\right) \leqslant g_{2}\left(x_{0}\right)$,

(ii) $g_{1}^{\prime}\left(x_{0}\right)<g_{2}^{\prime}\left(x_{0}\right)$,

(iii) $g_{1}^{\prime \prime}(x)>g_{2}^{\prime \prime}(x) \forall x>x_{0}$,

(iv) $\exists \bar{x}>x_{0}$ such that $g_{1}(\bar{x})>g_{2}(\bar{x})$.

Then there exists a unique point $\tilde{x} \in\left(x_{0}, \bar{x}\right)$ such that $g_{1}(\tilde{x})=g_{2}(\tilde{x})$.

Proposition 4. For $U(C)=\ln (C)$ and $f_{2}(L)=L^{\gamma}, \gamma>1$, the solution to the producers optimal money demand problem is unique, under any given positive sequence of wages $\left(w_{0}, w_{1}\right)$ and prices $\left(p_{0}, p_{1}\right)$.

Proof. Let $M_{1} \equiv x$ and solve for $M_{2}$ in terms of $M_{1}$ in (1) and (2) to get

$$
\begin{aligned}
& g_{1}(x)=\frac{p_{1}(1+\gamma \beta)}{w_{1}^{\gamma}} x^{\gamma}-\frac{\gamma \beta p_{0} p_{1} M_{0}^{\gamma}}{w_{0}^{\gamma} w_{1}^{\gamma}} x^{\gamma-1}, \\
& g_{2}(x)=\frac{\gamma \beta p_{1}}{(1+\gamma \beta) w_{1}^{\gamma}} x^{\gamma} .
\end{aligned}
$$

It is easy to check that with $x_{0}=0$ conditions (i)-(iv) of Lemma 3 are satisfied. This means that Eqs. (1) and (2) can be solved to find the unique solution $\mathbf{x}^{*}=\left(M_{1}^{*}, M_{2}^{*}\right)$ where

$$
\begin{aligned}
& M_{1}^{*}=\frac{\gamma \beta(1+\gamma \beta)}{\left(1+\gamma \beta+\gamma^{2} \beta^{2}\right)} p_{0} \frac{M_{0}^{\gamma}}{w_{0}^{\gamma}}, \\
& M_{2}^{*}=\frac{(\beta \gamma)^{1+\gamma}(1+\beta \gamma)^{\gamma-1}}{\left(1+\gamma \beta+\gamma^{2} \beta^{2}\right)^{\gamma}} \frac{p_{0}^{\gamma} p_{1}}{w_{1}^{\gamma} w_{0}^{\gamma^{2}}} M_{0}^{\gamma^{2}},
\end{aligned}
$$

which is the unique global maximum of our optimization problem with $U(C)=\ln C$ and $f(\bar{L})=\bar{L}^{\gamma}$.

\section{General equilibrium}

\subsection{Existence of competitive equilibrium}

Let $M_{0} \equiv \bar{M}>0$ be the total money stock and $\bar{L}>0$ be the labor endowment of Agent 1. 
Proposition 5. Let $U(C)=\ln C$ and $f(L)=L^{\gamma}$. There exists a competitive equilibrium of this economy which is characterized by

$$
\begin{aligned}
& w_{t}=\frac{\bar{M}}{\bar{L}} \quad \forall t, \\
& p_{0}=\frac{\bar{M}}{\overline{L^{\gamma}}} \frac{\left(1+\gamma \beta+\gamma^{2} \beta^{2}\right)}{\gamma \beta(1+\gamma \beta)}, \\
& p_{1}=\frac{\bar{M}}{\bar{L}^{\gamma}} \frac{(1+\gamma \beta)}{\gamma \beta}, \\
& p_{2}=\overline{p_{2}} \in\left(\frac{\bar{M}}{f(\bar{L})}, \infty\right), \\
& L_{t}^{d}=L_{t}^{s}=\bar{L} \quad \forall t, \\
& q_{t}^{d}=q_{t}^{s}=\frac{\bar{M}}{p_{t} \quad f o r t=0,1,} \\
& M_{1, t+1}=0 M_{2, t+1}=\bar{M} \quad \text { for } t=0,1, \\
& C_{1, t}=q_{t}^{d}=\frac{\bar{M}}{p_{t}} \quad \forall t, \\
& C_{2, t}=f(\bar{L})-\frac{\bar{M}}{p_{t}} \quad \text { for } t=0,1, \\
& C_{2, t}=f(\bar{L}), \quad t=2 .
\end{aligned}
$$

Proof. Money market clearing condition is met since we have $M_{2, t+1}=\bar{M}$ and $M_{1, t+1}=0$ for $t=0,1$. Such a money holding plan is feasible for Agent 2 since $\left(M_{1}^{*}, M_{2}^{*}\right) \in$ int $\Gamma$ which means budget constraints are satisfied at $\left(M_{1}^{*}, M_{2}^{*}\right)$. It is trivially feasible for Agent 1.

By Proposition 4 we know that this plan is optimal for Agent 2 if and only if the below two equations are satisfied:

$$
\begin{aligned}
& \bar{M}=\frac{\gamma \beta(1+\gamma \beta)}{\left(1+\gamma \beta+\gamma^{2} \beta^{2}\right)} p_{0} \frac{\bar{M}^{\gamma}}{w_{0}^{\gamma}}, \\
& \bar{M}=\frac{(\beta \gamma)^{1+\gamma}(1+\beta \gamma)^{\gamma-1}}{\left(1+\gamma \beta+\gamma^{2} \beta^{2}\right)^{\gamma}} \frac{p_{0}^{\gamma} p_{1}}{w_{1}^{\gamma} w_{0}^{\gamma^{2}}} M_{0}^{\gamma^{2}} .
\end{aligned}
$$

Labor market clearing conditions $L_{t}^{s}=\bar{L}=L_{t}^{d}=\bar{M} / w_{t} \forall t$ can be used to find the money wages $w_{t}$ :

$$
w_{0}=w_{1}=w_{2}=\frac{\bar{M}}{\bar{L}} .
$$


Substituting (5) into (3) and (4) equilibrium prices $p_{t}$ can be solved:

$$
\begin{aligned}
& p_{0}=\frac{\bar{M}}{\bar{L}^{\gamma}} \frac{\left(1+\gamma \beta+\gamma^{2} \beta^{2}\right)}{\gamma \beta(1+\gamma \beta)}, \\
& p_{1}=\frac{\bar{M}}{\bar{L}^{\gamma}} \frac{(1+\gamma \beta)}{\gamma \beta} .
\end{aligned}
$$

Optimality for Agent 1: (i) Supplying $\bar{L}>0$ for all $t$ is always optimal for Agent 1 because his utility is strictly increasing in $L_{t}^{s}$. To see this consider the Agent 1 's optimization problem:

$\max \sum_{t=0}^{T=2} \beta^{t} U\left(\frac{M_{t}-M_{t+1}}{p_{t}}+\frac{w_{t}}{p_{t}} L_{t}^{s}\right)$

s.t. for all $t$,

$$
\begin{aligned}
& \left(\frac{M_{t}-M_{t+1}}{p_{t}}+\frac{w_{t}}{p_{t}} L_{t}^{s}\right)=q_{t}^{d}, \\
& L_{t}^{s} \leqslant \bar{L}, \\
& M_{1, t+1}=M_{1, t}+w_{t} L_{t}^{s}-p_{t} q_{t}^{d},
\end{aligned}
$$

where $M_{t}, L_{t}^{s} \geqslant 0$ and $M_{1,0}=0$ is given. Since $w_{t} / p_{t}>0$ and $U^{\prime}()>0, U\left(\left(w_{t} / p_{t}\right) L_{t}^{s}\right)$ increases if $L_{t}^{s}$ increases. Therefore supplying $\bar{L}$ is optimal for Agent 1 .

(ii) Holding zero currency at each period is optimal for Agent 1, when the following condition is satisfied at each period:

$$
U^{\prime}\left(C_{t}\right)>\frac{p_{t}}{p_{t+1}} \beta U^{\prime}\left(C_{t+1}\right) .
$$

In period 0 , with $U(C)=\ln C$ and $C_{t}=\bar{M} / p_{0}, p_{t}=p_{0}, p_{t+1}=p_{1}, C_{t+1}=\bar{M} / p_{1}$ above condition becomes $\beta<1$ therefore it is automatically satisfied. For the other periods same argument applies.

Optimality for Agent 2 in the last period: Last period deserves attention. Agent 2 has two choices:

(i) Do not produce apples and use your money to purchase apples from the government at $\bar{p}_{2}$.

(ii) Hire labor $(\bar{L})$, produces $\left(f\left(\bar{M} / w_{2}\right)=f(\bar{L})\right)$ and consume it all.

For Agent 2 to hire labor and produce apples $\bar{p}_{2}$ must satisfy

$$
U\left(\frac{\bar{M}}{\bar{p}_{2}}\right)<U\left(f\left(\frac{\bar{M}}{w_{2}}\right)\right) .
$$

Since $U^{\prime}()>$.0 this means $\bar{p}_{2}>\bar{M} / f(\bar{L})$. So with the last periods price $p_{2}$ is set at $\bar{p}_{2}$, sufficiently high, Agent 2 will hire labor $\bar{L}$, produce $f(\bar{L})$ and consumes all. 
Government sells apples to Agent 1 at $\bar{p}_{2}$, thus Agent1 consumes $c_{1,2}=\bar{M} / \bar{p}_{2}$ which is clearly decreasing in $\bar{p}_{2}$.

Indeed the condition $\bar{p}_{2}>\bar{M} / f(\bar{L})$ is a profitability condition and should hold in each period. But when we look at the equilibrium prices $p_{0}, p_{1}$ we see that this condition is automatically satisfied for the other two periods as well.

It is now clear that Agents 1 and 2 are maximized at the described equilibrium.

Remark 6. Since we have $\bar{p}_{2} \in(\bar{M} / f(\bar{L}), \infty)$ the government can use arbitrarily small amount of resources to back the currency by setting $\bar{p}_{2}$ as high as she wishes.

Remark 7. We see that equilibrium prices $p_{0}$ and $p_{1}$ decrease with $\beta_{2}$ so with impatient firm type (low $\beta$ ) $p_{0}$ and $p_{1}$ will be higher at the equilibrium reducing the real value of apples.

\section{Quantitative analysis}

We can express the scale elasticity parameter as

$$
\gamma=\frac{A C}{M C} \text {. }
$$

Indeed, the equation above is an identity as we have for average cost:

$$
A C=\frac{w \bar{L}}{\bar{L}^{\gamma}}
$$

and for marginal cost

$$
M C=\frac{w \bar{L}^{1-\gamma}}{\gamma} .
$$

We can alternatively express the same elasticity as

$$
\gamma=\frac{A C}{M C}=\left(\frac{P}{M C}\right)\left(\frac{A C}{P}\right) .
$$

Therefore, based on the unique general equilibrium solution reported in Proposition 6 we can identify both the gross markup ratio $(P / M C)$ and the gross profit rate $(P / A C)$. For the second period $(t=1)$,

$$
(P / A C)_{1}=\frac{1}{\gamma \beta}+1
$$

and for the initial period $(t=0)$,

$$
(P / A C)_{0}=\frac{1}{\gamma \beta+(\gamma \beta)^{2}}+1 .
$$

Table 1 shows how, in our three period model, these ratios are effected as we vary the scale elasticity, $\gamma$, in the range, from 1.00 to 1.30 , that is compatible with estimates reported by Antweiler and Trefler (2000). 
Table 1

Finite horizon case

\begin{tabular}{llllll}
\hline & \multicolumn{1}{l}{$t=0$} & & & $t=1$ & \\
\cline { 2 - 3 } \cline { 5 - 6 }$\gamma$ & Markup $(P / M C)$ & Profit $(P / A C)$ & & Markup $(P / M C)$ & Profit $(P / A C)$ \\
\hline 1.0 & 1.54 & 1.54 & 2.05 & 2.05 \\
1.1 & 1.61 & 1.46 & 2.15 & 1.95 \\
1.2 & 1.69 & 1.41 & 2.25 & 1.87 \\
1.3 & 1.77 & 1.36 & 2.35 & 1.81 \\
\hline
\end{tabular}

Markup ratio and gross profit rate in the three period economy. Here we set $\beta=0.95$.

Although the rather high markup and profit rates in Table 1 are consistent with findings of Hall (1988), they are unreasonably large with regard to the findings of Basu and Fernald (1997). Basu and Fernald estimate a scale parameter of $\gamma=1.07$ for the durable goods manufacturing sector and a gross profit rate of slightly above 1.03, i.e. $3 \%$. The implied markup ratio, in view of Eq. (6) then is 1.10. Although these numbers cannot possibly be compatible with our three period model for empirically plausible values of beta in the range $[0.9,1]$, it is quite possible that in an infinite horizon version of our model, we would obtain much lower markup and average cost values. Indeed this can also be observed from Table 1 by the rise in profit and markup rate as the end of the economy approaches.

Following up from Remark 2, together with Eqs. (10) and (11) we can express the limiting value of the initial period's profit of a finite horizon economy when the horizon length grows to infinity as

$$
P / A C=\lim _{T \rightarrow \infty} \frac{1}{\sum_{i=1}^{T}(\gamma \beta)^{i}}+1 .
$$

Therefore in case $\gamma \beta<1$ the series in the denominator converges to $\gamma \beta /(1-\gamma \beta)$ so that the gross profit rate is given by

$$
P / A C=\frac{1}{\gamma \beta}
$$

in the infinite horizon case. But then the markup ratio calculated from $M C=\gamma A C$ turns out to be

$$
P / M C=\frac{1}{\beta} .
$$

It is now possible to observe the compatibility of our model's infinite horizon version and Basu and Fernald's (1997) finding of net economic profit rate (3\%) and the one standard deviation range for the scale elasticity estimate $1.05-1.09$. Table 2 reports the subjective discount parameters $\beta$ that are consistent with the empirical findings and the infinite horizon model solution. 
Table 2

Infinite horizon case

\begin{tabular}{llll}
\hline $\begin{array}{l}\text { Estimate of scale } \\
\text { elasticity }(\gamma)\end{array}$ & $\begin{array}{l}\text { Estimate of gross } \\
\text { profit }(P / A C)\end{array}$ & $\begin{array}{l}\text { Implied markup } \\
(P / M C)\end{array}$ & $\begin{array}{l}\text { Implied discount } \\
\text { factor } \beta\end{array}$ \\
\hline 1.05 & 1.03 & 1.08 & 0.92 \\
1.07 & 1.03 & 1.10 & 0.91 \\
1.09 & 1.03 & 1.12 & 0.89 \\
\hline
\end{tabular}

Discount rates implied by the model in order to be consistent with empirical profit and scale elasticities reported by Basu and Fernald (1997).

\section{Concluding remarks}

In this paper, we have observed

(1) Even under increasing returns to scale in production, price taking equilibrium may exist in a dynamic model with finance constraints,

(2) Standard Euler equations may continue to be useful in characterizing the optimum if the utility function is concave enough to avoid corner solutions,

(3) In a short lived economy, a significant positive amount of profits may remain to firm owners in general equilibrium.

(4) In the infinite horizon case, the profit shrinks to a small but positive amount for empirically reasonable technology and preference parameters.

In our example economy, the demand is unit elastic. Therefore a monopolistic equilibrium does not exist. However a price taking equilibrium, which in this case can also be thought of as a price cap set by a regulator, may exist. This price setting differs however from the practice of average cost pricing since some profits are left to the firm owners in the dynamic general equilibrium.

To interpret the equilibrium as genuinely competitive, the same model with more than one firms can be analyzed without any further technical problems. In such a case, however, the allocation of initial money endowment to the firms would crutially affect the profitability of the firms. Therefore interesting capital accumulation and dividend dynamics would emerge. This dynamic competition issue is left open as an interesting research area.

Concerning the structure of the model used here, our existence results are not directly comparable with the ones in the literature. Almost all of the general equilibrium papers on increasing returns use standard assumptions of the classical complete markets setup of the Arrow-Debreu model except for convexity of the production set. Existence issue is analyzed in this framework and results are obtained when firms follow special pricing rules without necessarily maximizing profits. Moreover, important part of the theory is devoted to the efficiency considerations (in the context of the second welfare theorem) which is not studied here. We, in a competitive setup with incomplete markets, show the existence of equilibrium under increasing returns with firm type agents making positive profits at all times. 
The basic explanation for this non-standard result is as follows. We assume that factor payments must be paid in cash and producer cannot use the money earned from selling output in the goods market within the same period, to pay for factor services. This limits the demand for labor. Therefore producer does not face unbounded profit opportunities because there is an upper bound on the labor input to be used in production. This limited participation assumption as well as the finite time horizons are responsible for our existence result.

If one looks at the equilibrium prices, one will see that the last period's price $\bar{p}_{2}$ can be set arbitrarily large without distorting the equilibrium. It is interesting to see in our model the possibility that even if the horizon is finite, individuals may want to hold money, under a negligible cost to the government of backing currency. Nevertheless, this result is a peculinarity of the logarithmic utility function.

It would be a natural extension to search for the competitive equilibrium with infinitely lived agents. Unfortunately, non-concavity of objective function causes problems in the application of dynamic programming techniques. Sotomayor (1987) claims that, under certain restrictions, the value function for the dynamic optimization problem (resulting from a discrete time one-good model of optimal accumulation) is concave and the optimal stationary policy exhibits properties similar to that obtained in the model where the technology is assumed to be convex. However later on Roy (1993) shows that the conditions on the utility and production function functions imposed in Sotomayor's paper are insufficient to ensure the results claimed about the concavity of the value function and other classical properties. These findings suggests that existence issue in infinite horizon models still deserves further investigation and it may very well be the case to have indeterminacy with infinite horizon. Nevertheless, concerning the structure of the model, the solution technique introduced and results obtained, our work is a new contribution to the literature when horizon is finite.

There are some papers dealing with existence of equilibrium under increasing returns but they are different in one important aspect; in the assumption on the type of increasing returns. They allow either an initial face of increasing returns or an aggregate increasing returns with individual firms having CRS technology (external economies of scale). For example Majumdar and Mitra (1993) have some existence results for a dynamic optimization example with a non-convex technology in the case of a linear objective function but the convexity is such that production function exhibits an initial phase of increasing returns. By imposing finance constraints on producers, we conjecture here that, such U-shaped average cost curves, as well as ever decreasing average cost functions, can be studied in a Walrasian setup.

\section{Acknowledgements}

We are grateful to Özgür Ceyhan, Ferhad Huseyinov, Ken Judd, Ismail Saglam, Kamil Yilmaz and two anonymous referees of this Journal for useful comments and suggestions. The usual disclaimer applies. 


\section{Appendix. The Inada condition cannot avoid corner solutions under IRTS}

Imposing the Inada Condition, $\lim _{c \rightarrow 0} U^{\prime}(C)=\infty$, on the utility function $U(C)$ (instead of Condition $(*)$ ) is not enough to ensure that the optimum will occur in the interior of the constraint set, $\Gamma$. Two typical examples are $U(C)=\ln C$ and $U(C)=\sqrt{C}$, both of which satisfy the so called 'Inada condition'. Somewhat surprisingly $U(C)=\sqrt{C}$ supports this conjecture. If one tries to solve Eqs. (1) and (2) with $U(C)=\sqrt{C}$ and $\gamma=2$ numerically, one will see that the existence of an interior solution depends on the parameter values. For example with all the parameters of interest $\left\{w_{t}, p_{t}, M_{0}\right\}_{t=0}^{T}$, except for $\beta$, set equal to one and with $\gamma=2$, FOC leads to the following set of equations to be solved:

$$
\begin{aligned}
& M_{2}=M_{1}^{2}-\frac{1}{4 \beta^{2}}, \\
& M_{2}=4 \beta^{2} M_{1}^{3}-\left(4 \beta^{2}-1\right) M_{1}^{2} .
\end{aligned}
$$

Equating (A.1) and (A.2) we get the cubic equation

$$
4 \beta^{2} M_{1}^{3}-4 \beta^{2} M_{1}^{2}+\frac{1}{4 \beta^{2}}=0
$$

which has double roots when $\beta>\beta_{\text {critical }}=\left(\frac{27}{64}\right)^{1 / 4}$. This means that for $\beta<\beta_{\text {critical }}$ Eq. (A.3) has no positive real solution at all.

The simple reason for $U(C)=\sqrt{C}$ be appearing as a counterexample is that the behavior of the value function $V\left(M_{1}, M_{2}\right)$ depends on the $\beta$ values. For $\beta<\beta_{\text {critical }}$, $V$ does not satisfy Condition $(*)$, which in fact is a sufficient condition. Following observations can be made.

Case 1: $0<\beta<\frac{1}{2}$. Global maximum is attained at the point $\tilde{\mathbf{x}}(\mathbf{0}, \mathbf{0})$ on the boundary.

Case 2: $\frac{1}{2} \leqslant \beta<\left(\frac{27}{64}\right)^{1 / 4}$.

The maximum is located at $\left(1-1 / 4 \beta^{2}, 0\right)$ on the boundary.

Case 3: $\beta \geqslant\left(\frac{27}{64}\right)^{1 / 4}$. In this case maximum occurs at $x^{*} \in$ int $\Gamma$. But there are two points which satisfy the first-order condition, i.e. Euler equations. We are sure that one of them will be the maximizer, but cannot immediately tell which.

What we observe here is that when $\beta$ is low $\left(\beta<\frac{1}{2}\right)$, the producer chooses to consume all the output in period 0 , that is, does not carry over currency to be used for the next period. As $\beta$ rises, Agent 2 discounts future consumption less and we observe a tendency towards a consumption smoothing behavior. For $\beta \geqslant \beta_{\text {critical }}$ we have $C_{0}, C_{1}, C_{2}>0$.

\section{References}

Antweiler, W., Trefler, D., 2000. Increasing returns and all that: a view from trade. NBER Working Paper, 7941.

Barth III, M.J., Ramey, V., 2001. The cost channel of monetary transmission. In: Bernanke, B.S., Rogoff, K. (Eds.), NBER Macroeconomics Annual 2001.

Başçı, E., Sağlam, I., 2003. On the importance of sequencing of markets in monetary economies. In: Sertel, M.R., Koray, S. (Eds.), Advances in Economic Design. Springer, Berlin. 
Basu, S., Fernald, J.G., 1997. Returns to scale in U.S. production: estimates and implications. Journal of Political Economy 105, 249-283.

Beato, P., 1982. The existence of marginal cost pricing equilibria with increasing returns. The Quarterly Journal of Economics 389, 669-688.

Blanchard, O.J., Kiyotaki, N., 1987. Monopolistic competition and the effects of aggregate demand. The American Economic Review 77, 647-666.

Brown, J., Geoffry, H.M., 1983. Marginal vs. Average cost pricing in the presence of a public monopoly. The American Economic Review 73, Issue 2, Papers and Proceedings of the 95th Annual Meeting of the American Economic Association, pp. 189-193.

Chamberlin, E.H., 1933. The Theory of Monopolistic Competition. Harvard University Press, Cambridge, MA.

Christiano, L.J., Eichenbaum, M., Evans, C.L., 1997. Sticky price and limited participation models: a comparison. European Economic Review 41, 1201-1249.

Christiano, L.J., Eichenbaum, M., Evans, C.L., 1998. Modeling money. NBER Working Paper, 6371.

Fuerst, T., 1992. Liquidity, loanable funds and real activity. Journal of Monetary Economics 29 (1), 3-24. Guesnerie, R., 1975. Pareto optimality in non-convex economies. Econometrica 45, 1-30.

Hall, R.E., 1988. The relation between price and marginal cost in US industry. Journal of Political Economy 96, 921-947.

Khan, A., Vohra, R., 1987. An extension of the second welfare theorem to economies with non-convexities and public goods. Quarterly Journal of Economics 102, 223-241.

Majumdar, M., Mitra, T., 1993. Dynamic optimization with a non-convex technology: the case of a linear objective function. The Review of Economic Studies 50, 143-151.

Mankiw, G., 1985. Small menu costs and large business cycles: a macroeconomic model of monopoly. Quarterly Journal of Economics 100, 529-539.

Roy, S., 1993. A note on income fluctuations and capital gains with a convex production function. Journal of Economic Dynamics and Control 18, 1199-1202.

Sotomayor, M.O., 1987. On income fluctuations and capital gains with a convex production function. Journal of Economic Dynamics and Control 11, 285-312.

Vohra, R., 1988. On the existence of equlibria in economies with increasing returns. Journal of Mathematical Economics 17, 179-192.

Vohra, R., 1992. Marginal cost pricing under bounded marginal returns. Econometrica 60, 859-876. 